\title{
Efeito do beneficiamento na qualidade fisiológica e sanitária de sementes do algodoeiro herbáceo ${ }^{1}$
}

\author{
Kilson P. Lopes ${ }^{2}$, Riselane de L. A. Bruno ${ }^{3}$, Rubens F. da Costa ${ }^{4}$, Genildo B. Bruno ${ }^{3}$ \& Maria do S. Rocha ${ }^{5}$
}

\begin{abstract}
RESUMO
Sementes de algodoeiro cvs. CNPA Precoce 2 e CNPA 7H, produzidas em campos irrigados do município de Touros, RN, safra 1998/99, foram submetidas, distintamente, ao descaroçamento, deslintamento mecânico e químico e, depois, acondicionadas em sacos de papel multifoliado, armazenadas em ambiente não controlado e em câmara seca, por 360 dias. Durante o armazenamento e em intervalos de 90 dias, realizaram-se avaliações da qualidade fisiológica e sanitária. O delineamento experimental foi inteiramente casualizado em parcela sub-subdividida, com quatro repetições, além de realizada a análise de variância e regressão polinomial. As sementes de ambas as cultivares, deslintadas quimicamente e mantidas em câmara seca preservaram suas qualidades fisiológicas pelo tempo de 270 dias de armazenamento. A maior preservação das sementes da cv. CNPA Precoce 2, descaroçadas, e as deslintadas mecanicamente, verificou-se em câmara seca; para as sementes da cv. CNPA $7 \mathrm{H}$, isto se verificou no material mantido em ambiente não controlado. $\mathrm{A}$ micoflora foi constituída pelos fungos do gênero Aspergillus.
\end{abstract}

Palavras-chave: Cossypium hirsutum L., deslintamento, viabilidade, vigor, micoflora

\section{Effects of seed processing on physiological and sanitary qualities of seeds of herbaceous cotton}

\begin{abstract}
Seeds of cotton cvs. CNPA Precoce 2 and CNPA 7H, produced under irrigated conditions in Touros Rio Grande do Norte State Brazil during the 1998/99 growing season were submitted to deseeding, mechanical or chemical delintering and then, packed in multi-layered paper bags and stored in a dry chamber or under room conditions during 360 days. Every 90 days, data on physiological and sanitary conditions of seeds were collected. The split plot design was employed, with four replications for each whole plot treatment arranged according to a completely randomized design. Collected data were analyzed by variance analysis and polynomial regression techniques. Chemically delinted seeds from both varieties, stored in dry chamber, preserved their physiological qualities until 270 days of storage. cv. CNPA Precoce 2 deseeded or mechanically delinted seeds kept better their physiological and sanitary conditions when stored in dry chamber. The same occurred for cv. CNPA 7H seeds when stored under room conditions. Seed mycoflora was constituted by Aspergillus.
\end{abstract}

Key words: Gossypium hirsutum L., delintering, seed viability, seed vigor, seed mycoflora

1 Parte da Dissertação de Mestrado do primeiro autor, apresentada à UFPB, Areia, PB

2 Rua Olegário Maciel 943, Monte Santo. CEP 58102-000, Campina Grande, PB. Fone: (83) 3322-5432. E-mail: kilsonlopes@uol.com.br

3 DF/CCA/UFPB. CEP: 58397-000, Areia, PB. CP 22. Fone: (83) 3337-1253. E-mail: lane@cca.ufpb.br

${ }^{4}$ EMEPA, PB, CEP: 58390-000, Alagoinha, PB. Fone: (83) 3278-1196. E-mail: rubens56@uol.com.br

${ }^{5}$ DEAg/UFCG. Fone: (83) 3322-5432. E-mail: marialirium@uol.com.br 


\section{INTRODUÇÃO}

Após a colheita, as sementes do algodoeiro se encontram revestidas por fibras longas, utilizadas no processo de fiação para tecelagem de vários tipos de tecido (Corrêa, 1989). A separação dessa fibra das sementes (caroços), é realizada através de máquinas dotadas de rolos ou serras, sendo tal prática denominada descaroçamento, a qual consiste na mais importante operação do beneficiamento do algodão (Clavijo, 1990 e Silva \& Carvalho, 1998).

Sementes recém-descaroçadas apresentam-se cobertas por grande quantidade de línter, camada fina de pelos curtos aderidos ao tegumento das sementes das variedades comerciais de algodoeiro herbáceo, constituindo-se num agravante nas práticas de beneficiamento, por dificultar a fluidez da massa de sementes: no armazenamento, por servir de abrigo para pragas e agentes patogênicos e, na semeadura, por afetar a uniformidade de distribuição das sementes, fazendo-se necessário o uso de um número maior de sementes e emprego de práticas onerosas, como o desbaste. De acordo com Medeiros Filho et al. (1995) e Vieira \& Beltrão (1999) a presença do línter reduz a capacidade de absorção de água pela semente, o que pode retardar a germinação.

O deslintamento caracteriza-se na eliminação total ou parcial do línter presente na semente, através do emprego dos processos: mecânicos, químicos e por flambagem. No Brasil, a maior parte da semente de algodoeiro produzida é deslintada mecanicamente; o deslintamento mecânico é realizado em máquinas dotadas de serras que, através de movimentos rotativos, retiram parte do línter presente na superfície da semente, não sendo suficiente para permitir o processamento em máquinas beneficiadoras. No deslintamento mecânico podem ocorrer danos às sementes, facilitando a entrada de microrganismos, o que afetará a germinação e a capacidade de armazenamento das sementes (Vieira \& Beltrão, 1999 e Pádua \& Vieira, 2001).

Os processos de deslintamento químico, realizados após o mecânico, seja por via úmida $\left(\mathrm{H}_{2} \mathrm{SO}_{4}\right)$ ou seca $(\mathrm{HCl})$, são eficientes, rápidos e desintegram completamente o línter (FAPAMG, 1997), possibilitando o beneficiamento das sementes em mesa de gravidade e garantindo um lote de sementes com alto valor cultural. Diversos autores afirmam que sementes deslintadas com ácido sulfúrico apresentam maior velocidade de emergência no campo, maior porcentagem de germinação e vigor (Fallieri et al., 1995; Paolinelli et al., 1995; Queiroga et al., 1997 e Souza, 2000).

A preservação e a conservação das safras agrícolas representam uma questão absolutamente vital. Segundo FAPAMG (1997), o potencial de armazenamento da semente é influenciado, em grande parte, pela sua qualidade inicial antes do armazenamento, e por sua própria estrutura e características genéticas; no entanto, para garantir que as características das sementes sejam mantidas, faz-se necessário um rigoroso controle do ambiente de armazenagem, principalmente com relação à umidade e temperatura.

Estudos conduzidos por Paolinelli \& Braga (1997), avaliando alterações na qualidade de sementes de algodão durante o armazenamento, mostraram interações altamente significativas entre níveis de vigor e períodos de armazenamento.

Em relação aos fungos de armazenamento, algumas espécies de Aspergillus e Penicillium são comuns e causam danos às sementes de várias espécies durante o armazenamento (Patrício, 1991). É crescente o significativo papel que esses fungos exercem no processo deteriorativo de sementes, causando reduções parciais e/ou totais da viabilidade.

Ante o abordado objetivou-se, com o presente trabalho, avaliar a qualidade fisiológica e sanitária de sementes de algodoeiro das cultivares CNPA Precoce 2 e CNPA 7H, submetidas a diferentes processos de deslintamento e condições de armazenamento, pelo tempo de 360 dias.

\section{MATERIAL E MÉTODOS}

Este trabalho foi realizado no Laboratório de Análise de Sementes do Departamento de Fitotecnia da Universidade Federal da Paraíba, Campus II, em Areia, PB, em parceria com o Centro Nacional de Pesquisa do Algodão, da Empresa Brasileira de Pesquisa Agropecuária (CNPA/EMBRAPA) Campina Grande, PB.

Foram utilizadas sementes fiscalizadas de algodoeiro, cultivares CNPA Precoce-2 e CNPA 7H, produzidas no ano agrícola 1998/99, em campos irrigados pelo sistema de pivô central, na Fazenda Bebida Velha, município de Touros, RN. Após a colheita, o algodão em rama foi beneficiado em descaroçadores de serra na Usina Algodoeira da EMBRAPAAlgodão, na Estação Experimental de Patos, PB, em que suas sementes descaroçadas (DS), foram consideradas testemunha. Após o descaroçamento, sementes com línter foram processadas em deslintadores mecânicos da Usina Algodoeira de Pedro Avelino, RN, constituindo o tratamento (DM) representado pelas sementes de algodão deslintadas mecanicamente. Sementes descaroçadas e depois deslintadas de maneira mecânica, foram submetidas ao deslintamento químico (DQ) por via úmida com ácido sulfúrico, na proporção de 7 kg de sementes para $1 \mathrm{~L}$ de ácido concentrado (p.a.), durante 5 minutos, seguido de lavagem em água corrente para retirada do excesso do ácido. Após secagem natural por 12 h, foram submetidas ao processo de classificação em mesa de gravidade da Usina de Beneficiamento de Sementes da Empresa Estadual de Pesquisa Agropecuária (EMEPA-PB), em Alagoinha-PB.

As sementes dos diferentes tratamentos foram acondicionadas em sacos de papel multifoliado, com capacidade para $1 \mathrm{~kg}$, e armazenadas por um ano, em condições ambientais não controladas (Figura 1) e em câmara seca. Durante o armazenamento no ambiente não controlado, as temperaturas apresentaram amplitude entre 22,61 e 31,79 ${ }^{\circ} \mathrm{C}$, enquanto a umidade relativa variou de 67,12 e 79,63\%; em câmara seca a umidade relativa média foi de $65 \%$ e temperatura de $20^{\circ} \mathrm{C}$.

Para se avaliar a qualidade das sementes, obtiveram-se amostras por ocasião do acondicionamento e a cada 90 dias durante o armazenamento, sendo submetidas às seguintes avaliações: 
Grau de umidade: realizado pelo método da estufa a $105 \pm 3{ }^{\circ} \mathrm{C}$, durante $24 \mathrm{~h}$, segundo as Regras para Análise de Sementes (Brasil, 1992), utilizando-se quatro repetições por tratamento. Os resultados do grau de umidade (base úmida) foram expressos em porcentagem.

Germinação: conduzida com quatro repetições de 50 sementes por tratamento, em rolos de papel Germitest, embebidas em água destilada, na proporção de 2,5 vezes o peso do papel seco, em germinador a temperatura constante de $25^{\circ} \mathrm{C}$. As avaliações nos $4^{\circ}$ e $12^{\circ}$ dias foram realizadas após a instalação do teste, de acordo com as Regras para Análise de Sementes (Brasil, 1992). Antes da semeadura, as sementes foram imersas em solução de hipoclorito de sódio, a uma concentração de $10 \%$, durante 10 min e logo após lavadas em água corrente.

Primeira contagem de germinação: realizada aproveitando-se o teste de germinação descrito anteriormente. Os resultados foram expressos em porcentagem de plântulas normais.

Índice de velocidade de germinação (IVG): estabelecido juntamente com o teste de germinação. As avaliações das plântulas normais foram realizadas diariamente, a partir da primeira contagem de germinação. O índice de velocidade de germinação foi calculado mediante a fórmula proposta por Maguire (1962).

Micoflora das sementes: realizada com quatro repetições de 50 sementes para cada tratamento e incubadas empregando-se o blotter test (Neergaard, 1979). As sementes, em número de 10, foram distribuídas no interior de placas de Petri, sobre três discos de papel de filtro previamente umedecidos com água destilada e esterilizada e mantidos em câmara com temperatura de $24 \pm 2{ }^{\circ} \mathrm{C}$, onde permaneceram sob regime de iluminação com fotoperíodo de 12 h, proporcionado por lâmpadas de radiação próxima ao ultravioleta (NUV) durante oito dias. A identificação e a contagem dos fungos foram realizadas examinando-se as colônias fúngicas desenvolvidas nas sementes, sob microscópio estereoscópio.

O delineamento estatístico utilizado no experimento foi o inteiramente casualizado em parcela sub-subdividida com quatro repetições, sendo a parcela representada pela interação (duas cultivares x três processos de beneficiamento), a sub-parcela pelos dois ambientes de armazenamento e a subsubparcela pelos cinco períodos de armazenamento. As variáveis que caracterizavam a qualidade fisiológica das sementes foram todas submetidas a análise de variância, com desdobramento das somas de quadrado dos efeitos em regressão polinomial, utilizando-se o sistema para análise estatística SAEG (2000). Os dados em porcentagem foram transformados em arco seno $\sqrt{x / 100}$, exceto a primeira contagem de germinação.

\section{RESULTADOS E DISCUSSÃO}

Nas Tabelas 1 e 2 encontra-se o resumo da análise de variância do presente experimento, podendo-se constatar efeitos significativos para a maioria das variáveis estudadas.

Os dados climáticos referentes ao ambiente não controlado, encontram-se na Figura 1. Observa-se que os maiores valores de temperatura (máxima e mínima) foram atingidos aos 180 dias, oportunidade em que a umidade relativa esteve mais baixa.

Tabela 1. Análise de variância e coeficiente de variação (CV) para umidade (UMI), germinação (GER), primeira contagem de germinação (PCG) e índice de velocidade de germinação (IVG) de sementes de duas cultivares de algodoeiro submetidas a diferentes beneficiamentos e condições de armazenamento

\begin{tabular}{|c|c|c|c|c|c|}
\hline \multirow{2}{*}{ Fontes de variação } & \multirow{2}{*}{ GL } & \multicolumn{4}{|c|}{ Quadrado Médio } \\
\hline & & UMI ${ }^{1}$ & GER ${ }^{1}$ & PCG & IVG \\
\hline Cultivar (C) & 1 & $2,81753^{\star \star}$ & $342,1737 * \star$ & 2381,4 ** & $20,7211^{\star *}$ \\
\hline Deslintamento (D) & 2 & $6,38358 * *$ & $441,9003 * \star$ & 10126,47 ** & 39,2039 ** \\
\hline$C \times D$ & 2 & $0,241658 * *$ & $4,6374^{\mathrm{ns}}$ & $186,2^{* *}$ & $1,30926^{\text {ns }}$ \\
\hline Erro (a) & 18 & 0,028940 & 11,2088 & 32,1 & 0,74320 \\
\hline Ambiente $(A)$ & 1 & 62,5567 ** & 87,3796 ** & $601,6667 * \star$ & $0,47704^{\mathrm{ns}}$ \\
\hline$A \times C$ & 1 & $3,45082^{* *}$ & $260,1359 * *$ & $448,2667^{\text {ns }}$ & $11,6777^{* *}$ \\
\hline$A \times D$ & 2 & $1,63631 * *$ & $49,8277^{\star *}$ & $32,0667 * *$ & $1,34570 *$ \\
\hline$A \times C \times D$ & 2 & $0,27817 * *$ & 103,8358 ** & 105,8667 ** & $1,4027^{*}$ \\
\hline Erro (b) & 18 & 0,01788 & 9,43359 & 19,1889 & 0,3945 \\
\hline Período (P) & 4 & 14,9647 ** & $763,9809 * \star$ & 3218,642 ** & 22,4203 ** \\
\hline $\mathrm{P} \times \mathrm{C}$ & 4 & $0,41744^{* *}$ & $251,3442^{* *}$ & $1479,942 * \star$ & 7,8456 ** \\
\hline$P \times D$ & 8 & $0,81602^{* \star}$ & $162,6219 * *$ & $858,3417^{* *}$ & $9,7679 * *$ \\
\hline$P \times A$ & 4 & $5,635896^{\star *}$ & $16,6485^{\text {ns }}$ & $200,9583^{* *}$ & $0,65153^{\text {ns }}$ \\
\hline$P \times C \times D$ & 8 & $0,12895^{\mathrm{ns}}$ & $78,8846^{*}$ & $384,1167^{* *}$ & $3,0306^{*}$ \\
\hline$P \times C \times A$ & 4 & $1,04805^{\star *}$ & $66,4693^{*}$ & $570,0583^{* *}$ & $2,3808^{*}$ \\
\hline$P \times D \times A$ & 8 & $0,69814^{\star *}$ & $48,5276^{\mathrm{ns}}$ & $110,2333^{*}$ & $1,2752^{n s}$ \\
\hline$P \times C \times D \times A$ & 8 & $0,40499 * *$ & $48,7848 *$ & $124,9083^{*}$ & $2,2686^{*}$ \\
\hline Resíduo & 144 & 0,0347 & 12,6964 & 28,5333 & 0,5677 \\
\hline CV (\%) & & 1,02 & 5,82 & 9,53 & 8,52 \\
\hline
\end{tabular}


Tabela 2. Análise de variância e coeficiente de variação (CV) para incidência dos fungos Aspergillus flavus (AFL), Aspergillus niger (ANI), Aspergillus sp. (ASP) e Fusarium sp. (FUS) em sementes de duas cultivares de algodoeiro, submetidas a diferentes beneficiamento e condições de armazenamento

\begin{tabular}{|c|c|c|c|c|c|}
\hline \multirow{2}{*}{ Fontes de variação } & \multirow{2}{*}{ GL } & \multicolumn{4}{|c|}{ Quadrados Médios } \\
\hline & & $\mathrm{AFL}^{1}$ & ANI ${ }^{1}$ & ASP $^{1}$ & FUS 1 \\
\hline Cultivar (C) & 1 & 584,1077 ** & 273,8021 ** & $72,19 \mathrm{~ns}$ & 5,411199 ns \\
\hline$C \times D$ & 2 & 701,6610 ** & $243,2293 * \star$ & $335,2738 * *$ & $5,096518^{\text {ns }}$ \\
\hline Erro (a) & 18 & 28,86811 & 9,878185 & 26,93366 & 4,977312 \\
\hline Ambiente $(A)$ & 1 & $20,34123^{\mathrm{ns}}$ & $3,431637^{\mathrm{ns}}$ & $30,53383^{\mathrm{ns}}$ & $0,4431104^{\mathrm{ns}}$ \\
\hline$A \times D$ & 2 & $24,73232^{\mathrm{ns}}$ & $36,67133^{\text {ns }}$ & 189,6071 ** & $5,534425^{\mathrm{ns}}$ \\
\hline$A \times C \times D$ & 2 & 101,4738 ** & $13,23799^{n s}$ & $48,89261^{\mathrm{ns}}$ & $16,23731^{*}$ \\
\hline Erro (b) & 18 & 12,95165 & 15,43518 & 22,18759 & 4,750554 \\
\hline Período (P) & 4 & 1925,870 ** & $291,6939 * *$ & $351,6766^{\star *}$ & $20,31277^{* *}$ \\
\hline$P \times C$ & 4 & $91,4848^{\mathrm{ns}}$ & $103,5254^{\star}$ & $33,5148^{\mathrm{ns}}$ & $6,66634^{\mathrm{ns}}$ \\
\hline$P \times D$ & 8 & 200,6588 ** & $118,0369 * *$ & $59,3303^{\text {ns }}$ & $22,8609 * *$ \\
\hline$P \times C \times D$ & 8 & $487,4662^{\star *}$ & $15,2564^{\mathrm{ns}}$ & $64,5841^{\mathrm{ns}}$ & $7,5624^{\mathrm{ns}}$ \\
\hline$P \times C \times A$ & 4 & 474,9922 ** & $16,2248^{\mathrm{ns}}$ & $73,5986^{\text {ns }}$ & $14,5860^{\mathrm{ns}}$ \\
\hline$P \times D \times A$ & 8 & $567,9429 * *$ & $11,0040^{\text {ns }}$ & $41,5935^{\mathrm{ns}}$ & $0,65834^{\mathrm{ns}}$ \\
\hline$P \times C \times D \times A$ & 8 & $290,1993^{* *}$ & $20,1099^{n s}$ & $32,8599^{\text {ns }}$ & $11,0776^{\mathrm{ns}}$ \\
\hline Resíduo & 144 & 31,5585 & 16,0625 & 25,8334 & 4,9988 \\
\hline CV (\%) & & 28,74 & 141,50 & 74,258 & 1,16 \\
\hline
\end{tabular}

** $e^{*}$ - Significativo a 1 e $5 \%$ de probabilidade pelo teste $F$, respectivamente
ns - Não significativo

${ }^{1}$ Dados transformados em arc sen $\sqrt{x / 100}$

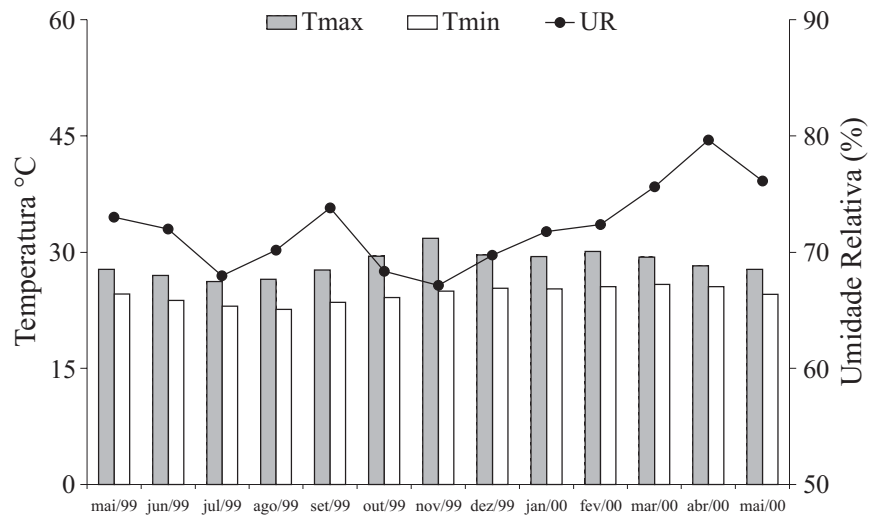

Período de Armazenamento

Figura 1. Dados médios mensais de temperatura (máxima e mínima) e umidade relativa, referentes ao período de armazenamento de sementes de algodoeiro (Gossypium hirsutum L.) cv. CNPA Precoce 2 e CNPA 7H, em ambiente não controlado

Sementes de algodão das cvs. CNPA Precoce 2 e CNPA 7H, após descaroçamento, deslintamento mecânico e deslintamento químico apresentaram, no início do armazenamento, teores de umidade inferiores a 10\% (Figura 2), estando dentro do padrão da CESM-PB (1989) e FAPAMG (1997). No decorrer do armazenamento, esses valores indicaram variações podendo-se constatar que, sob condições de ambiente não controlado, sementes de ambas as cultivares submetidas aos demais processos de beneficiamento apresentaram, aos 180 dias, os valores mais baixos de umidade (em torno de $8 \%$ ), período no qual se registraram os maiores valores de temperatura e baixa umidade relativa (Figura 1). Após aquele período até o final do armazenamento, o acrés- cimo no grau de umidade das sementes foi pronunciado, principalmente naquelas deslintadas quimicamente. Sementes da cv. CNPA Precoce 2 apresentaram, no final do armazenamento, valores superiores a $10 \%$, sem dúvida pelo fato das sementes deslintadas quimicamente se encontrarem mais desprotegidas e mais susceptíveis às condições adversas de temperatura e umidade (Arantes et al., 2000).

Em condições de câmara seca, sementes das duas cultivares de algodoeiro, independente do beneficiamento a que foram submetidas, apresentaram variações mínimas nos valores de umidade durante o armazenamento, apesar de se registrar um acréscimo ao longo do armazenamento, quando estas sementes submetidas aos deslintamentos mecânico e químico atingiram valores médios de umidade superiores a $10 \%$, logo aos 180 dias de armazenamento.

Dentre os processos de beneficiamento empregados, sementes de ambas as cultivares descaroçadas, apresentaram os menores valores de umidade, independente do ambiente de armazenamento, durante todo o período e sementes deslintadas quimicamente, indicaram maiores valores de umidade ao final do armazenamento, para a cv. CNPA Precoce 2 , independente do ambiente de armazenamento e para a cv. CNPA 7H em ambiente não controlado. Esses resultados confirmam os relatos de Medeiros Filho (1995) e Vieira \& Beltrão (1999), de que a presença do línter dificulta a absorção de água pela semente servindo-lhe, portanto, como forma de proteção.

A germinação das sementes do algodoeiro dessas duas cultivares apresentou, no início do armazenamento, valores médios de germinação superiores a 70\% (Figura 3) acima, portanto, do limite de tolerância (60\%) estabelecido pela CESM-PB (1989) para sementes do algodoeiro herbáceo. 


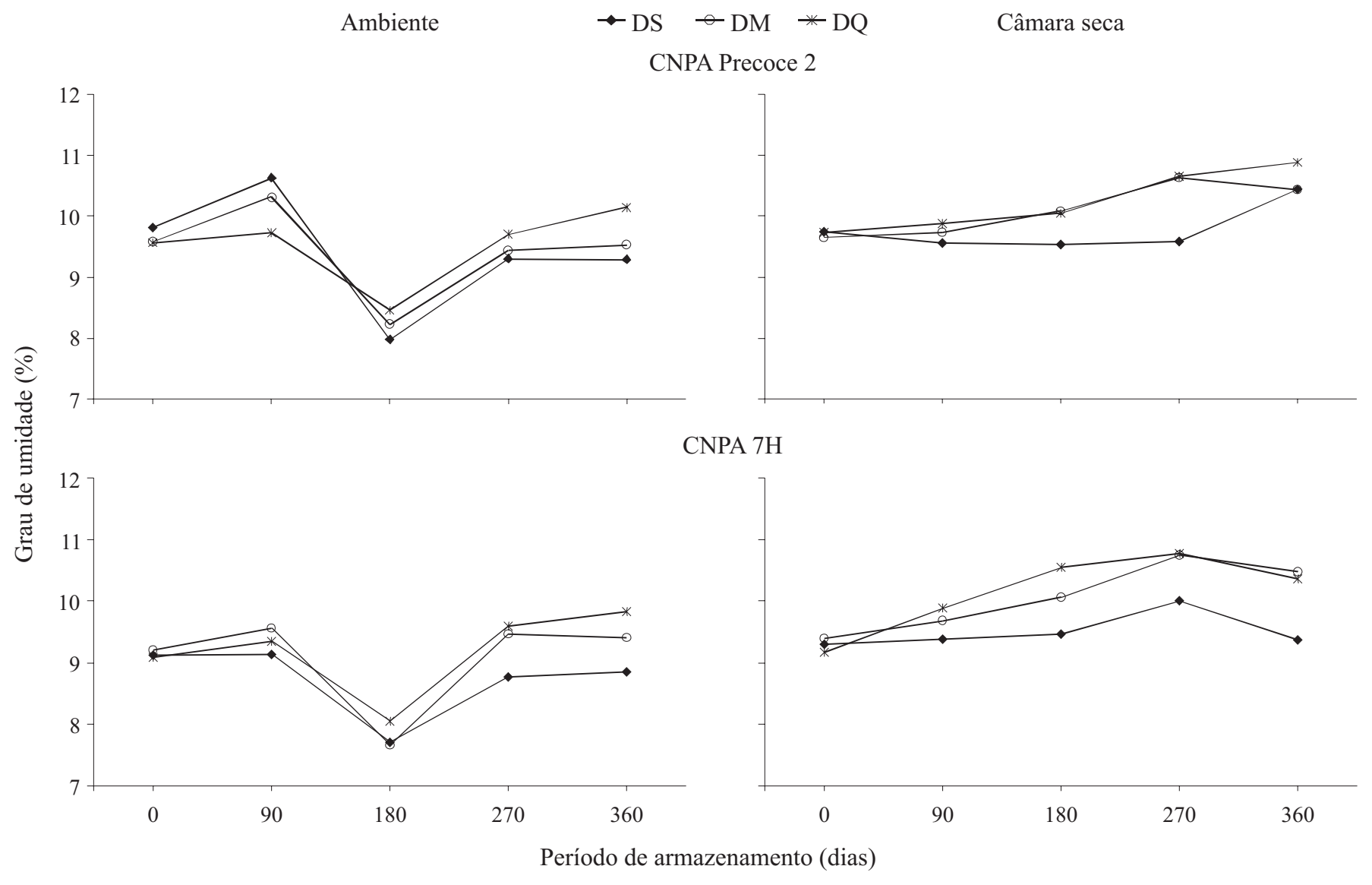

Figura 2. Grau de umidade de sementes de algodão cvs. Precoce 2 e CNPA-7H, descaroçadas (DS), deslintadas mecanicamente (DM) e deslintadas quimicamente (DQ), durante 360 dias de armazenamento

Dentre as sementes estudadas, pode-se observar que aquelas da cv. CNPA Precoce 2 apresentaram os maiores valores de germinação (Figura 3) por um período maior de armazenamento (170 dias), em particular quando submetidas ao deslintamento químico e armazenadas em câmara seca alcançando, ao final do armazenamento, germinação em torno dos $80 \%$. Referidos resultados, apresentados pelas sementes deslintadas quimicamente durante o armazenamento, foram também observados por Medeiros Filho et al. (1996) e Queiroga et al. (1997).

No que diz respeito à germinação das sementes da cV. CNPA 7H (Figura 3), verifica-se uma rápida perda de viabilidade, com menos de 100 dias de armazenamento, quando mantidas em ambiente não controlado, independente do beneficiamento, chegando ao final com germinação inferior a $60 \%$. Aquelas sementes quando mantidas em câmara seca,preservaram sua viabilidade durante todo o período de armazenamento, com exceção das deslintadas quimicamente que, ao final do período, mostraram valores de germinação em torno de $40 \%$. Os resultados podem estar relacionados com a ocorrência de fungos fitopatogênicos, decorrentes de condições não apropriadas ao armazenamento daquelas sementes (Sobreira et al., 1990).

O deslintamento químico ocasionou, às sementes das duas cultivares, os maiores valores de germinação nas condições em que foram armazenadas, exceto as sementes da cv. CNPA 7H que, em condições de câmara seca, apresentaram redu- ção na germinação, a partir de 270 dias de armazenamento; no entanto, a câmara seca foi o ambiente no qual se verificou a menor perda de viabilidade das sementes, o que pode ser constatado pelas curvas de regressão, as quais se mostraram mais suaves naquelas condições, com exceção das sementes da cv. CNPA 7H, deslintadas quimicamente. Esses resultados estão de acordo com Medeiros Filho et al. (1996) e Sousa et al. (1997), que constataram que o armazenamento das sementes de algodoeiro deslintadas em condições controladas de câmara seca, foi mais favorável à manutenção da qualidade fisiológica.

O comportamento apresentado pelas curvas de regressão do vigor caracterizado pela primeira contagem de germinação das sementes do algodoeiro cv. CNPA Precoce 2 (Figura 4), demonstra que, apesar de apresentarem, de início, resultados inferiores aos da cv. CNPA $7 \mathrm{H}$, com o passar dos períodos de armazenamento, aquelas sementes tenderam a aumentar e manter o vigor em níveis elevados, dos 90 aos 270 dias de armazenamento, principalmente quando submetidas ao deslintamento químico e mantidas em câmara seca, resultados que concordam com os encontrados por Medeiros Filho et al. (1996) e Souza (2000). Este fato se deve, possivelmente, à superação da dormência pós-colheita daquelas sementes.

Sementes da cv. CNPA Precoce 2 deslintadas mecanicamente, embora apresentem o máximo de vigor em torno de $64 \%$, mantiveram-no por até 240 dias, quando armazenadas 
Ambiente

$\rightarrow \mathrm{DS} \quad-\mathrm{DM} \rightarrow \mathrm{DQ}$

CNPA Precoce 2
Câmara seca

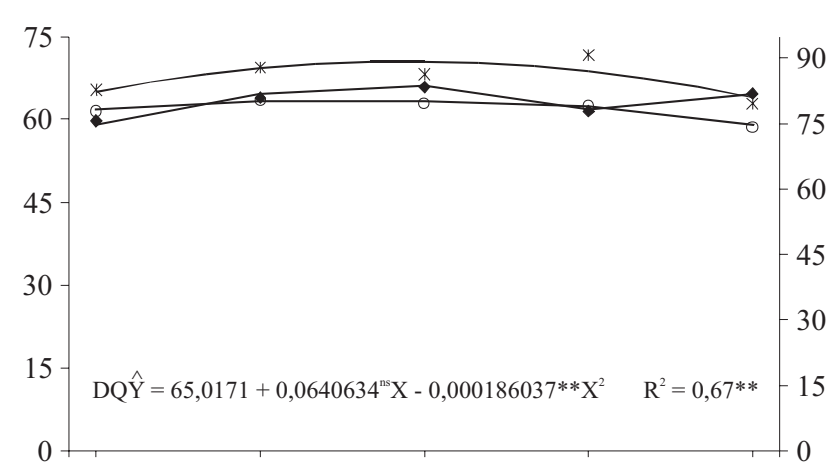

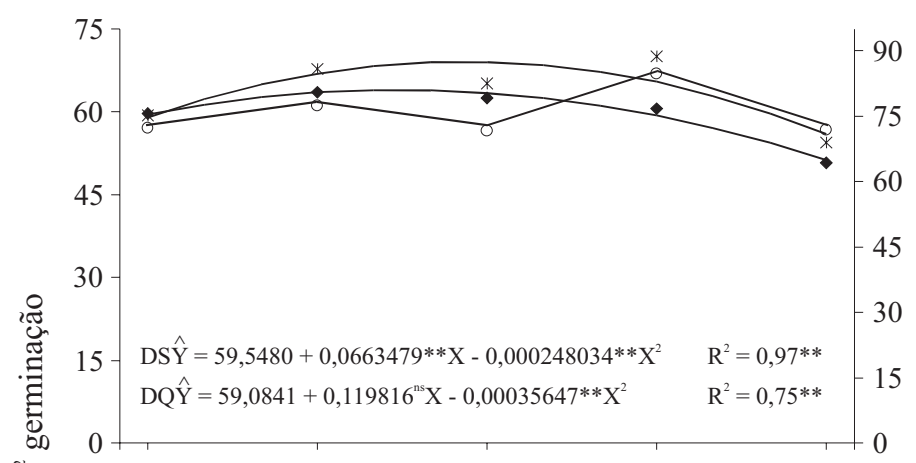

CNPA 7H

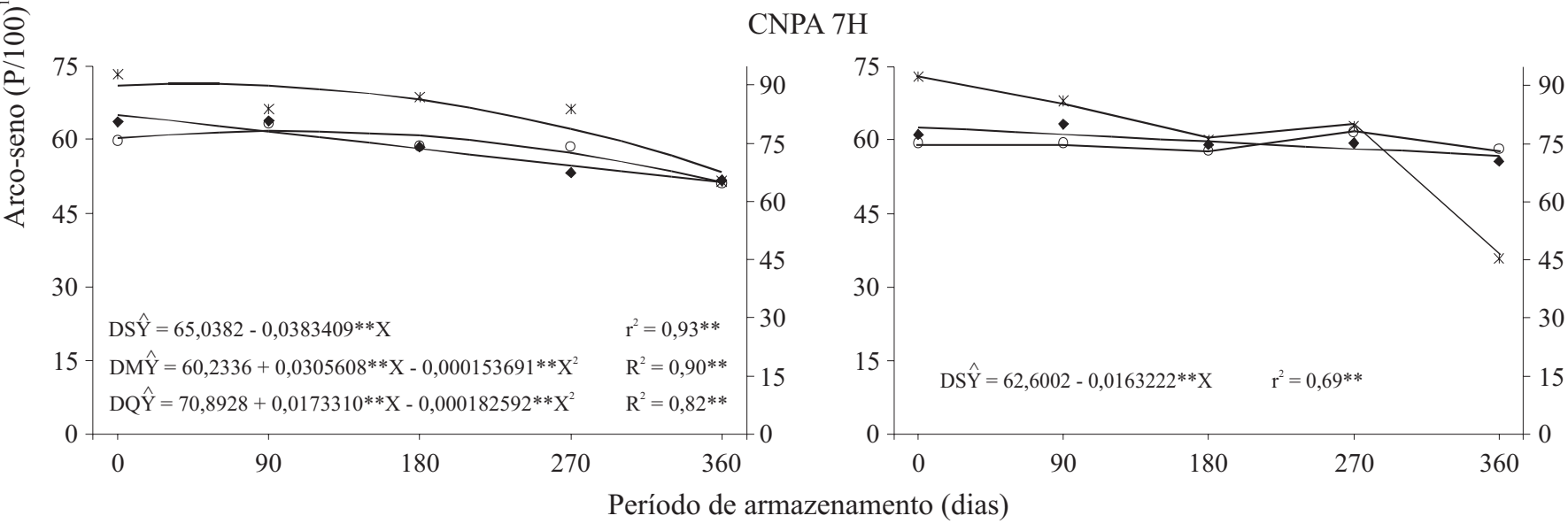

Figura 3. Germinação de sementes de duas cultivares do algodoeiro, submetidas ao descaroçamento (DS), ao deslintamento mecânico (DM), ao deslintamento químico (DQ) e ao armazenamento, durante 360 dias

sob condições de ambiente não controlado, e de $72 \%$ por até 220 dias, quando armazenadas em câmara seca. Esses resultados concordam com os obtidos por Dutra \& Castro (1997), que verificaram que, em condições ambientais, sementes de algodoeiro cv. CNPA Precoce 2 mantiveram sua qualidade fisiológica.

No que se refere à cv. CNPA 7H, sementes deslintadas quimicamente e armazenadas sob condições controladas ou não (Figura 4), se destacaram mais uma vez dentre os demais tratamentos, garantindo um vigor em torno de $75 \%$, por volta dos 150 dias de armazenamento. Após este período, registraram-se reduções no vigor, sobretudo quando armazenadas em câmara seca. A superioridade do vigor verificado nas sementes deslintadas quimicamente, foi constatada por Queiroga et al. (1997).

As sementes do algodoeiro da cv. CNPA Precoce 2 (Figura 5) apresentaram, de forma geral, maiores índices de velocidade de germinação, quando comparadas com as sementes da cv. CNPA 7H, comportamento semelhante ao da primeira contagem de germinação (Figura 4). Este comportamento foi mais evidente nas sementes submetidas ao deslintamento químico, apresentando vigor máximo aos 180 e 270 dias de armazenamento, sob condições de câmara seca e ambiente não controlado, respectivamente. A baixa velocidade de germinação das sementes com línter quando comparadas com sementes deslintadas, pode estar relacionada com a diminuição da velocidade de absorção de água daquelas sementes durante a germinação, conforme relatam Vieira \& Beltrão (1999).

Referente às sementes da cv. CNPA 7H observam-se, pelas curvas de regressão (Figura 5), reduções mais acentuadas de vigor, independente do beneficiamento empregado. Quando mantidas sob condições ambientais não controladas, registraram-se reduções no vigor, a partir dos 140 dias, para sementes deslintadas mecanicamente e acentuado declínio ao longo do armazenamento, para as submetidas ao descaroçamento, sendo possível o ajuste de uma equação linear para 0 vigor dessas sementes. No que diz respeito às sementes deslintadas quimicamente, pôde-se constatar que, independente das condições de armazenamento empregadas, as mesmas apresentaram perda no vigor, a partir dos 110 dias de armazenamento, apesar das reduções serem mais pronunciadas quando tais sementes foram mantidas sob condições de câmara seca.

Observa-se que, de maneira geral, sementes submetidas ao deslintamento químico, apresentaram os maiores valores de vigor, independente da cultivar e das condições de armazenamento empregadas, concordando com os resultados de Medeiros Filho (1995).

Na análise sanitária das sementes de algodoeiro, antes do armazenamento (período zero das Figuras 6 a 8), foram encontrados os fungos: Aspergillus flavus nas sementes de 
Ambiente

$\rightarrow \mathrm{DS} \rightarrow \mathrm{DM} \quad * \mathrm{DQ}$

Câmara seca

CNPA Precoce 2
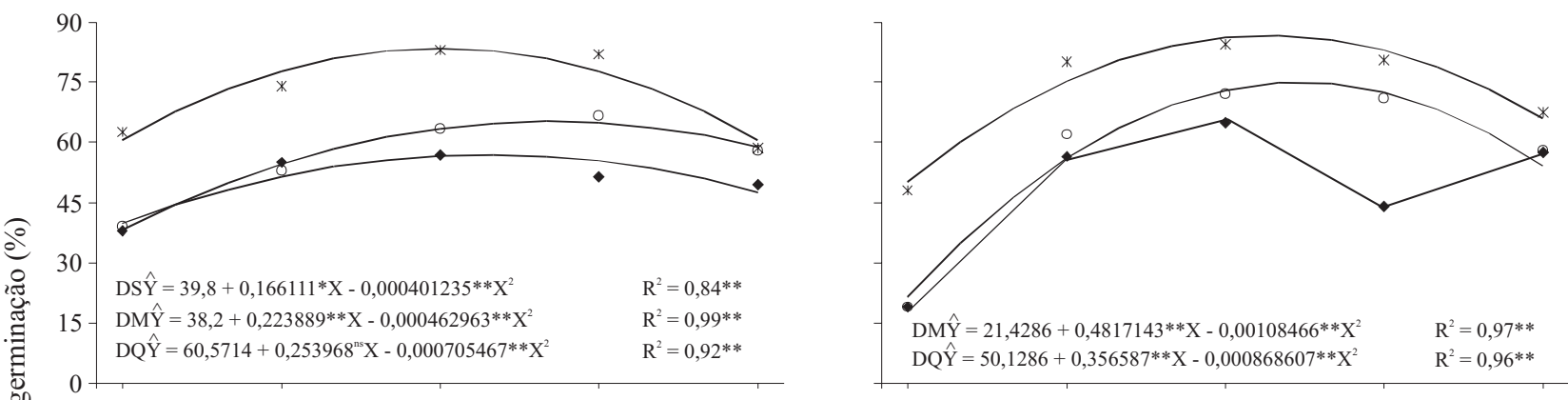

CNPA 7H
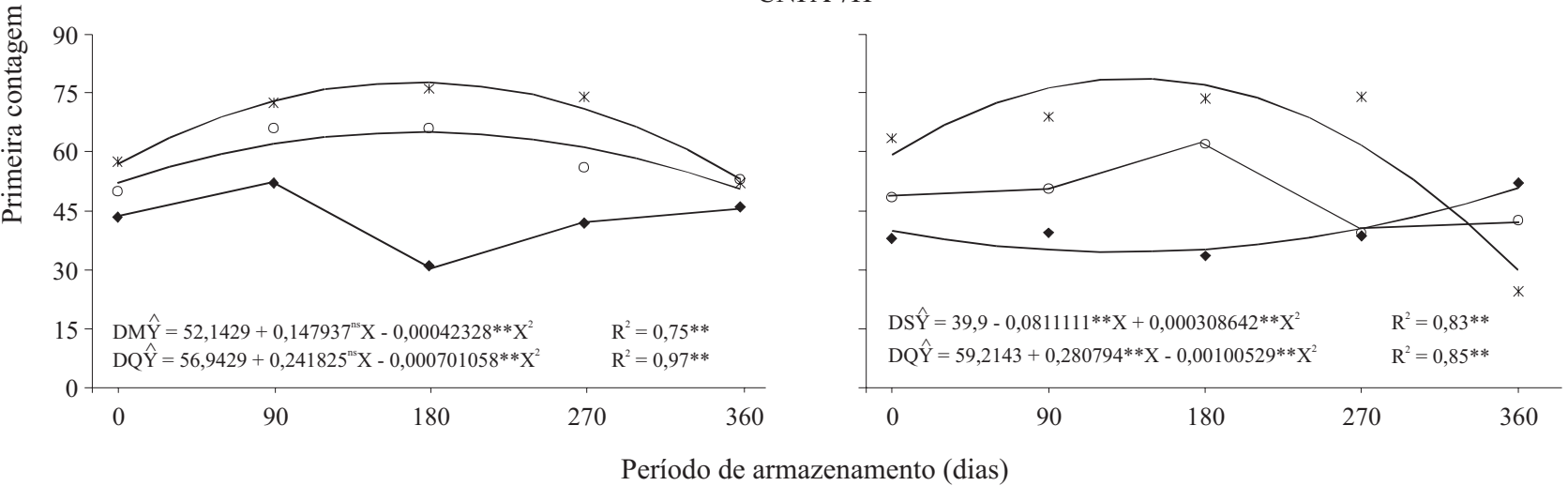

Figura 4. Porcentagem da primeira contagem de germinação de sementes de duas cultivares do algodoeiro, submetidas ao descaroçamento (DS), ao deslintamento mecânico (DM) e ao deslintamento químico (DQ) e ao armazenamento, durante 360 dias

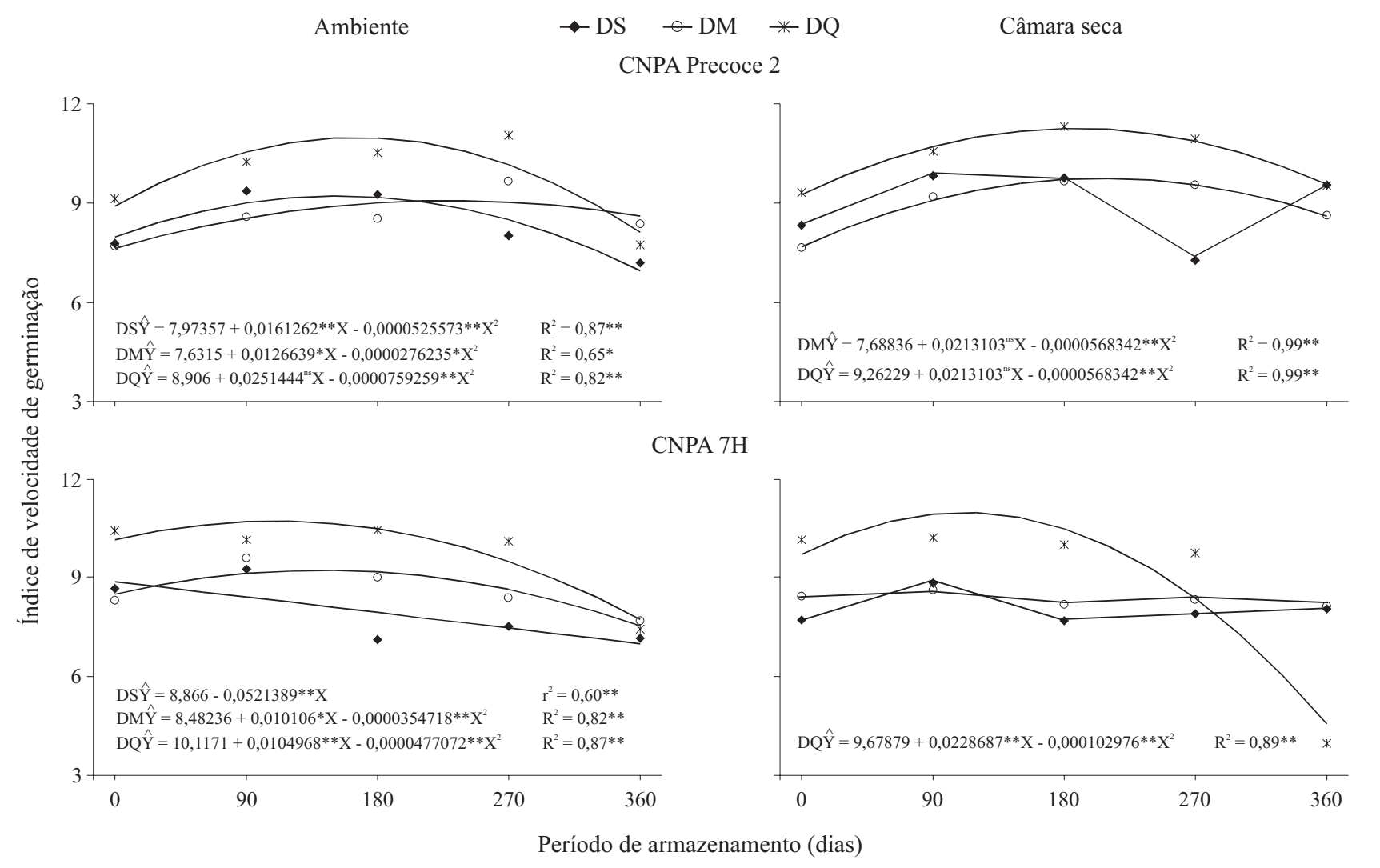

Figura 5. Índice de velocidade de germinação (IVG) de sementes de duas cultivares do algodoeiro, submetidas ao descaroçamento (DS), ao deslintamento mecânico (DM) e ao deslintamento químico (DQ) e ao armazenamento, durante 360 dias 
Efeito do beneficiamento na qualidade fisiológica e sanitária de sementes do algodoeiro herbáceo

Ambiente

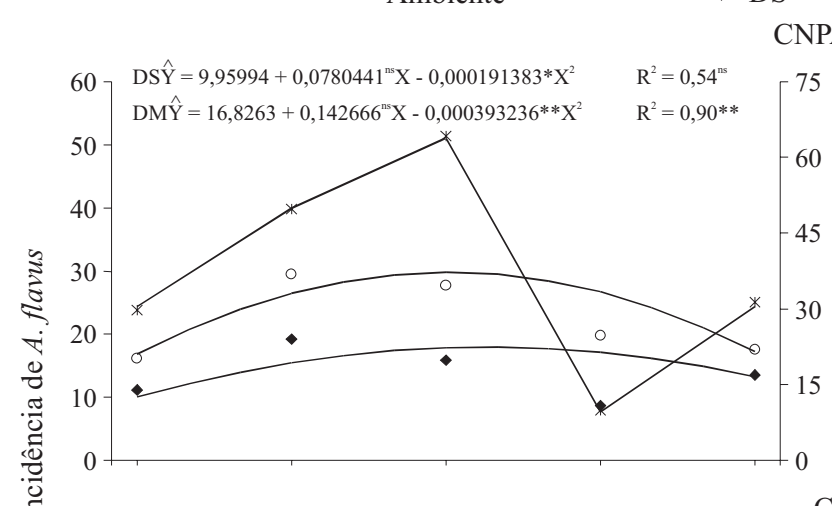

NPA Precoce 2

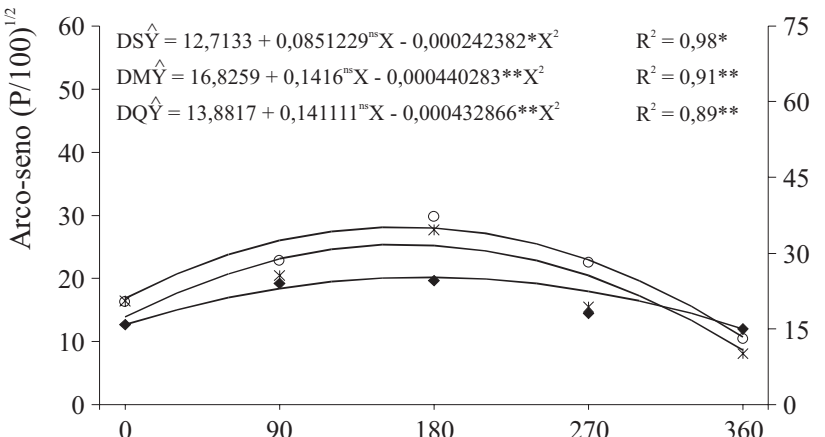

CNPA $7 \mathrm{H}$
Câmara seca
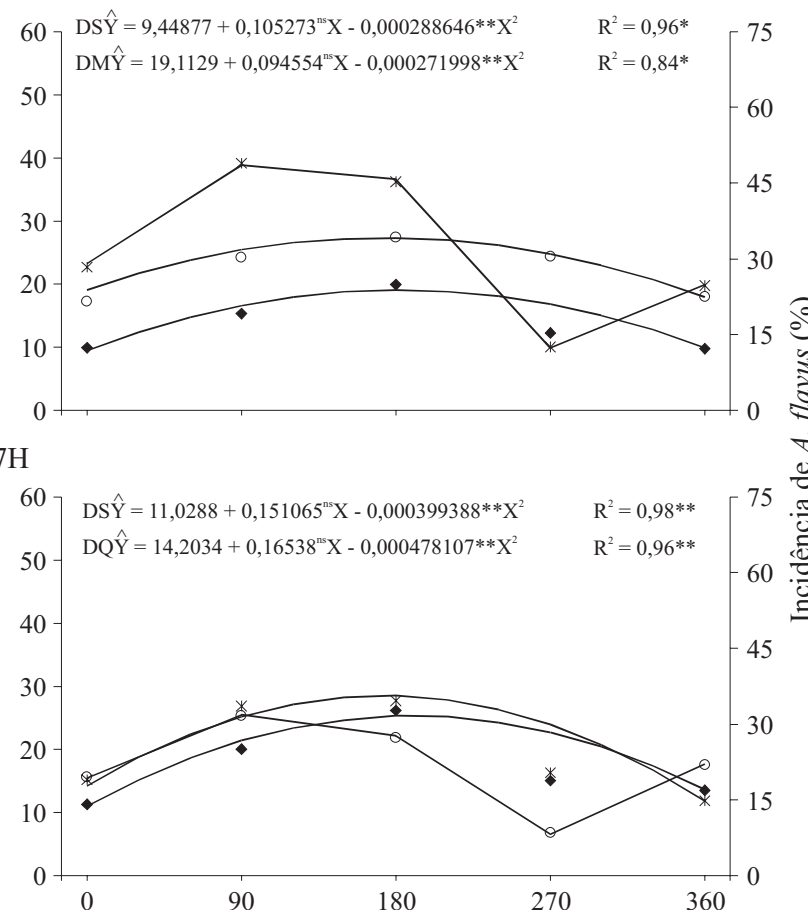

Período de armazenamento (dias)

Figura 6. Incidência de Aspergillus flavus em sementes de duas cultivares do algodoeiro submetidas ao descaroçamento (DS), ao deslintamento mecânico (DM) e ao deslintamento químico (DQ) e ao armazenamento, durante 360 dias

Ambiente

$$
\rightarrow \mathrm{DS} \multimap \mathrm{DM} \rightarrow \mathrm{DQ}
$$

\section{CNPA Precoce 2}

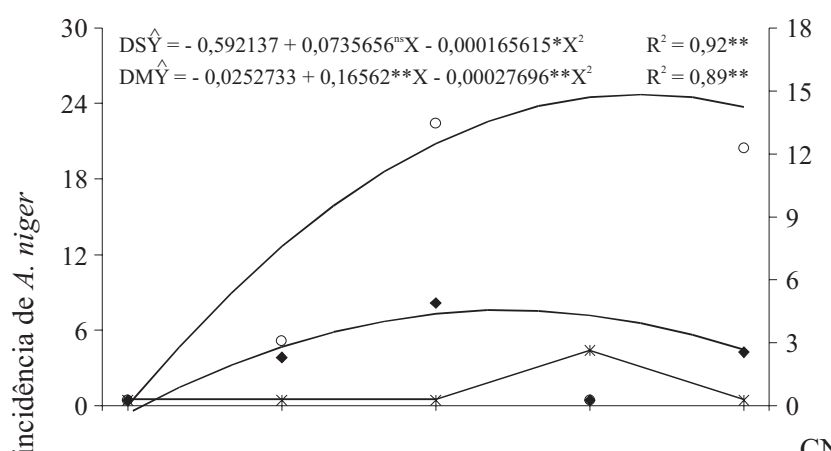

CNPA $7 \mathrm{H}$
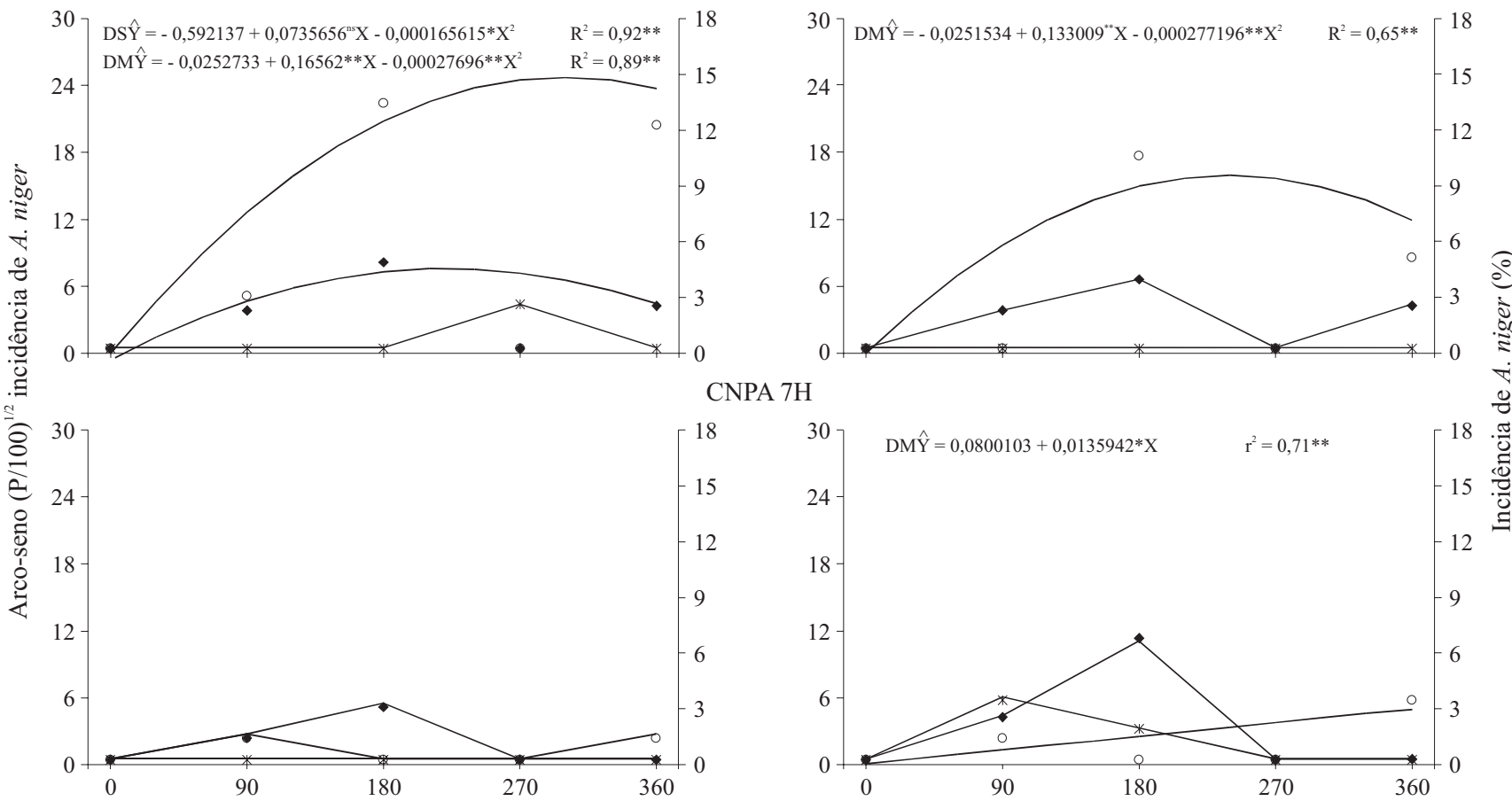

Período de armazenamento (dias)

Figura 7. Incidência de Aspergillus niger em sementes de duas cultivares do algodoeiro submetidas ao descaroçamento (DS), ao deslintamento mecânico (DM) e ao deslintamento químico (DQ) e ao armazenamento, durante 360 dias

R. Bras. Eng. Agríc. Ambiental, v.10, n.2, p.426-435, 2006. 
ambas as cultivares estudadas, independente do beneficiamento a que foram submetidas e o Aspergillus sp. nas sementes descaroçadas e deslintadas mecanicamente das duas cultivares e nas sementes deslintadas quimicamente da cv. CNPA 7H. Os Aspergilli, tidos como um dos principais agentes de deterioração das sementes armazenadas, segundo Patrício (1991) e Pádua \& Vieira (2001) ocorrem com elevada incidência nas sementes dessas cultivares.

As incidências de $A$. flavus foram mais elevadas nas sementes da cv. CNPA Precoce 2, mantidas em ambiente não controlado, principalmente aquelas submetidas ao deslintamento químico (Figura 6), idêntido aos resultados encontrados por Arantes et al. (2000). Conforme se observa também na Figura 6, em ambas as cultivares as maiores incidências de A. flavus foram registradas aos 180 dias de armazenamento; nas observações subseqüentes, verificaram-se reduções nas incidências desse fungo. As sementes submetidas ao descaroçamento, apresentaram as menores incidências do fungo, independente da cultivar ou da condição de armazenamento empregada.

Com relação ao fungo $A$. niger, observado durante o armazenamento (Figura 7), as maiores incidências se verificaram nas sementes da cv. CNPA Precoce 2, submetidas ao deslintamento mecânico e ao descaroçamento principalmente quando armazenadas em condições ambientais não controladas. Os maiores valores foram obtidos aos 180 dias de armazenamento, nas sementes submetidas ao descaroçamento e armazenadas em câmara seca.
Dentre os beneficiamentos, o deslintamento químico foi o responsável pelas menores incidências desse fungo nas sementes, nas duas cultivares e condições de armazenamento, chegando a apresentar incidência (zero) na maior parte das amostragens realizadas durante o período de armazenamento (Figura 7).

A incidência de Aspergillus sp. nas sementes do algodoeiro cv CNPA Precoce 2 (Figura 8), foi maior quando submetidas ao descaroçamento e ao deslintamento mecânico. Para este último, os maiores valores foram registrados nas sementes amostradas aos 180 e 270 dias, mantidas na câmara seca e ambiente não controlado, respectivamente; nas sementes descaroçadas, mantidas em ambiente não controlado, verificou-se aumento continuado da incidência, ao longo do armazenamento.

As sementes da cv. CNPA Precoce 2 deslintadas quimicamente apresentaram as menores incidências de Aspergillus sp., nessas condições, durante a maior parte do armazenamento, porém aos 270 dias foram registrados valores próximos aos 12\% (Figura 8). De acordo com Luca Filho (1985), a atividade desses fungos é regulada pelas condições ambientais, durante o período de armazenamento e pelas condições do lote de sementes.

Ainda com relação ao Aspergillus sp., para a cv. CNPA 7H as maiores incidências ocorreram nas sementes mantidas em câmara seca que apresentaram, ao longo do armazenamento, tendência linear (regressão) de aumento. O observado mostra

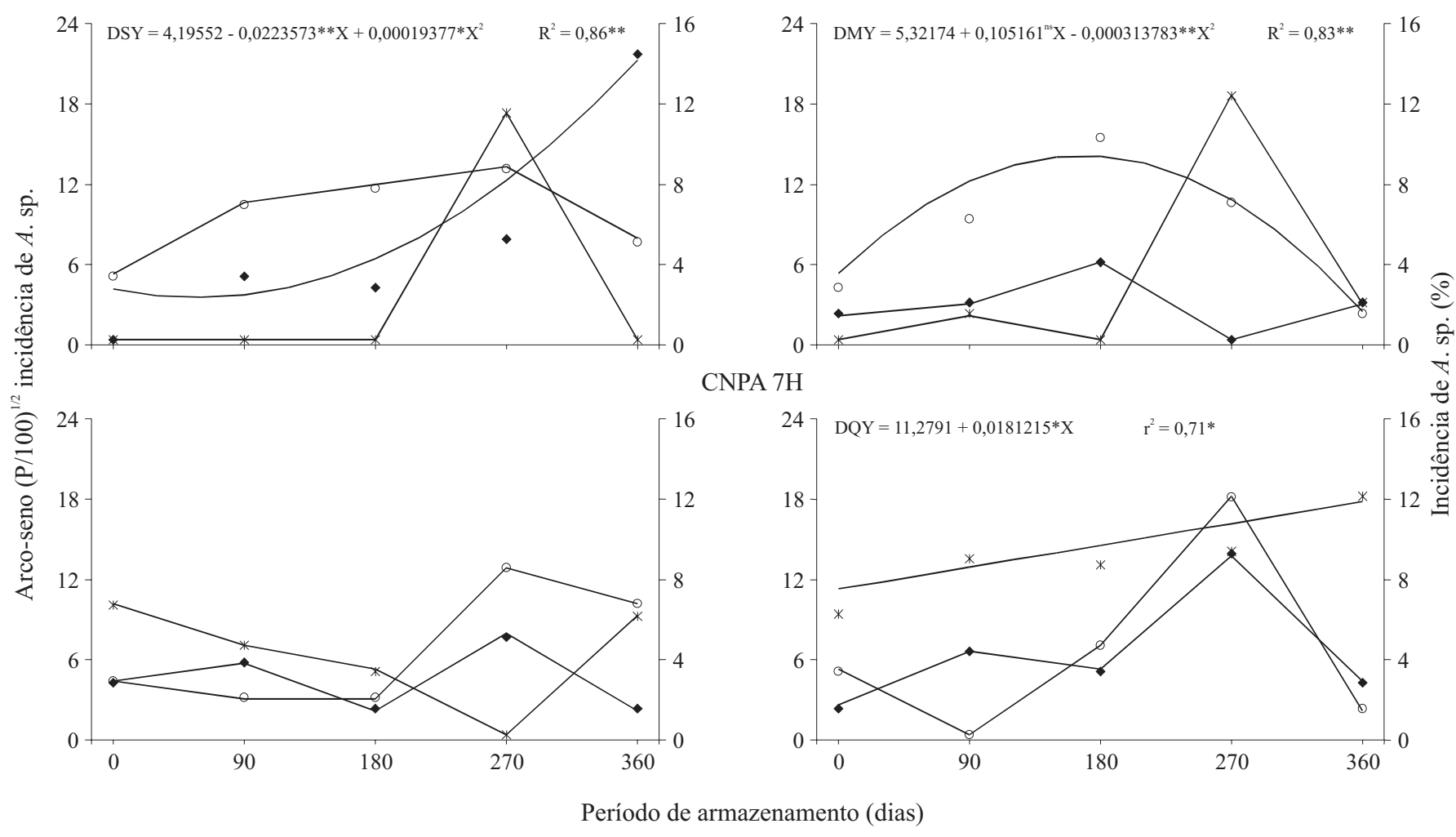

Figura 8. Incidência de Aspergillus sp. em sementes de duas cultivares do algodoeiro submetidas ao descaroçamento (DS), ao deslintamento mecânico (DM) e ao deslintamento químico (DQ) e ao armazenamento, durante 360 dias 
possível influência desse fungo no decréscimo do poder germinativo e do vigor (Figuras 3, 4 e 5) das sementes deslintadas da cv. CNPA 7H, quando armazenadas em câmara seca, pois em condições ambientais se verificou a manutenção e/ou redução da incidência do Aspergillus sp. até os 270 dias nas sementes deslintadas quimicamente e até os 180 dias nas descaroçadas, assim como nas deslintadas mecanicamente.

\section{CONCLUSÕES}

1. O deslintamento químico e o armazenamento em câmara seca das sementes de algodoeiro garantem a manutenção de suas qualidades fisiológicas, até os 270 dias.

2. Sementes descaroçadas apresentam menor capacidade germinativa e vigor.

4. Durante o armazenamento verificou-se, em ordem decrescente de valores de incidência registrada, a ocorrência dos fungos A. flavus, A. niger e Aspergillus sp.

5. Sementes de algodoeiro, independente do beneficiamento empregado, são susceptíveis à contaminação por fungos de armazenamento, principalmente os do gênero Aspergillus.

\section{LITERATURA CITADA}

Arantes. H. A. G.; Cícero, S. M.; Novembre, A. D. L. C. Encapsulação: Efeitos sobre a germinação e sanidade das sementes de algodão. Scientia Agricola, Piracicaba, v.57, n.1, p.81-88, 2000.

Brasil. Ministério da Agricultura. Regras para análise de sementes. Brasília: DNDV/CLAV, 1992. 365p.

CESM-PB. Delegacia Federal de Agricultura da Paraíba. Normas técnicas para a produção de sementes e mudas fiscalizadas. 3.ed. João Pessoa: DFARA, 1989. 85p.

Clavijo, C. A. Desmote. In: Federación Nacional de Algodoneros. (Bogotá, Colombia). Bases Técnicas para el cultivo del algodón en Colombia. Bogotá: Guadalupe, 1990, p.633-653.

Corrêa, J. R. V. Algodoeiro: Informações básicas para o cultivo. Belém: EMBRAPA-UEPAE, 1989. 29p. Documentos, 11

Dutra, A. S.; Castro, J. R. Qualidade de sementes de algodão herbáceo, em função do grau de umidade e condições de armazenamento na sua conservação. In: Congresso Brasileiro do Algodão, 1.,1997. Fortaleza. Anais... Campina Grande: EMBRAPA-CNPA, 1997, p.591-592.

Fallieri, J.; Paolinelli, G. P.; Saraiva, H. A. B.; Braga, S. J. Avaliação da qualidade de sementes deslintadas de algodão em ambientes e embalagens. Informativo ABRATES, Brasília, v.5, n.2, p.41, 1995. Edição Especial

FAPAMG - Fundação de Apoio à Pesquisa Agropecuária de Mato Grosso. Mato Grosso: Autosuficiência, eficiência e ciência. Algodão no caminho do sucesso. Rondonópolis: Fundação MT, 1997, 107p. Boletim de Pesquisa, 01

Luca Filho, O.A. Importância da sanidade na produção de sementes de alta qualidade. Revista Brasileira de Sementes, Brasília, v.7, n.1, p.113-123, 1985.
Maguire, J. D. Speed of germination aid in solution and evaluation for seedling emergence and vigor. Crop Science, Madison, v.2, n.1, p.176-177, 1962.

Medeiros Filho, S.; Fraga, A. C.; Carvalho, M. L. M.; Mendes, A. N. G.; Vieira, M. G. G. C. Avaliação da qualidade fisiológica de sementes de algodão submetidas a deslintamento químico e beneficiamento. Ciência e Prática, Lavras, v.19, n.4, p.357-364, 1995.

Medeiros Filho, S. Fraga, A. C.; Queiroga, V. P.; Sousa, L. C. F. Efeito do armazenamento sobre a qualidade fisiológica de sementes deslintadas do algodão. Ciência e Agrotécnica, Lavras, v.20, n.3, p.284-292, 1996.

Neergaard, P. Seed pathology. 2.ed. London: The MacMillan Press, v.2. 1979. 1191p.

Pádua, G. P.; Vieira, R. D. Deterioração de sementes de algodão durante o armazenamento. Revista Brasileira de Sementes. Brasília, v.23, n.2, p.255-262, 2001.

Paolinelli, G. P.; Braga, S. J. Alterações da qualidade de sementes de algodão armazenadas com dois níveis de vigor. Informativo ABRATES, Curitiba, v.7, n.1/2, p.168, 1997.

Paolinelli, G. P.; Braga, S. J.; Fallieri, J.; Saraiva, H. A. B. Efeito comparativo de diferentes processos de deslintamento sobre a qualidade de sementes de algodoeiro herbáceo. Informativo ABRATES, Brasília, v.5, n.2, p.64, 1995.

Patrício, F. R. A. Efeito do deslintamento a flama sobre a qualidade fisiológica e a sanidade de sementes de algodão. Piracicaba: ESALQ, 1991. 122p. Dissertação Mestrado

Queiroga, V. de P.; Beltrão, N. E. de M.; Patriota, A. R. T. Influência dos processos de beneficiamento na germinação de sementes de algodão (Gossypium hirsutum L. r latifolium, Hutch), armazenadas. In: Congresso Brasileiro do Algodão,1,1997, Fortaleza. Anais... Campina Grande: EMBRAPACNPA, 1997. p.584-587.

SAEG. Sistema para análise estatística; versão 8.0. Viçosa: Fundação Arthur Bernardes, 2000.

Silva, R. R. F. S.; Carvalho, O. F. Beneficiamento do algodão. In: EMBRAPA. Centro de Pesquisa Agropecuária do Oeste. Algodão: informações técnicas. Dourados: EMBRAPA CPAO; Campina Grande: EMBRAPA-CNPA, 1998. 267p. Circular Técnica, 7

Sobreira, D. G.; Machado, J. C.; Vieira, M. G. C. Ocorrência de fungos e qualidade fisiológica de alguns lotes de sementes de algodão (Gossypium hirsutum L.) produzidas no Estado de Minas Gerais, safra 1985/86. Ciência e Prática, Lavras, v.14, n.3, p.317-325, 1990.

Sousa, J. G. A.; Queiroga, V. de P.; Mata, M. E. R. M. C. Interação entre colheita, beneficiamento e armazenamento na germinação das sementes de algodão herbáceo (Gossypium hirsutum L.). Engenharia na Agricultura, Voçosa, v.5, n.2, p.194-207, 1997.

Souza, A. A. Influência do horário de colheita e do extrato de aroeira na qualidade de sementes do algodoeiro herbáceo. Areia: UFPB, 2000, 90p. Dissertação Mestrado

Vieira, R. M.; Beltrão, N. E. de M. Produção de sementes de algodoeiro. In: Beltrão, N. E. de M. O agronegócio do algodão no Brasil. Campina Grande: EMBRAPA-CNPA. v.1. 1999. p.430-453. 